\title{
Book Review of My Heart will Triumph by Mirjana SoldoCocoa
}

\author{
Samuel A Nigro* \\ Case Western Reserve University, School of Medicine, USA \\ *Corresponding author: Samuel A Nigro,Case Western Reserve University, School of Medicine, Ohio, USA
}

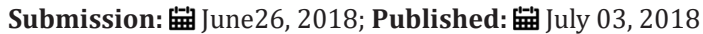

\section{Opinion}

A beloved high school sweetheart of the 1950s asked me to review this book.It is the story of the apparitions of the Virgin Mary to six children in Medugorje, Yugoslavia (now Sarajevo) which began June 24, 1981.The author lived it and describes it.It is a startling peek of Eternity and life outside of space-time.I find it provides the basis for contemporary parables of basic physics and science which help in understanding the universe consistent with ancient parables helping people know there is more than all the entropy and synthesis of our daily lives in space/time.Similar are current scientific theories of multiple universes seeming to confirm the Church's ancient proposed multiverses of Heaven, Purgatory, and Hell.

My Heart Will Triumph is another glimpse of Spirituality proving the pre-Big Bang Statimuum, which is the word in basic physics for "Eternity with God"-or "Heaven." Mirjana stated, "Scientists, I later learned, categorized our experience as being in a state of ecstasy.I called it being in Heaven" (page 29).This is confirmed by wide-eyed onlookers repeatedly viewing the children ascending, gliding in less than two minutes to the top of the hill to see the Virgin, a walking distance adults said would take them "at least 12 minutes to get there (page 28).”What Soldo details is amazing.Who knows why these kids got apparitions so vividly.Maybe because one can find no hint of fabrication, division, evil, degradation or exploitation in anything in the book about these kids (Good gentle childhoods without adult sex and violence have consequences).Indeed, these kids bland acceptance of intimidating and demanding abuse by ubiquitous Communist authorities evokes the relaxed sainthood imagery of St. Thomas More facing his decapitation by King Henry VIII because of infallible-knowledge providing immunity and total undisturbed solace.As always, Communists, Pharisees, scribes, Herodians, atheists, secularists, and other jealous angry editors have not the faintest idea of the reality that there is more to life than their short-sighted arrogance.

It was rough on the kids-peers and adults avoided and openly rejected them and their families for the most part because there were unpleasant consequences for those who were accepting and nice to them.What childhoods:ignored, bullied and threatened with murder...but all accepted with benign revering composure because they witnessed real Spirituality (As the Virgin told them "For those who will live the word of my Son and who will love, death will be life" page 59)."During those days, I was ready to die at any moment.I expected it was all leading to a point where they would kill me; I would vanish overnight.I wasn't afraid of dying, though, because then I could be with the Blessed Mother forever" (page 117)-in the Statimuumby the way.

The book details "the visionaries" as they were called.What they heard from the Virgin must be read directly; a reviewer cannot do them justice.Most chapters begin with a quote from the Virgin as a title for the chapter.Many more quotes in each chapter from the Virgin offer a touch of the Divine throughout the book enabling many minutes of supernatural reflection and Spirit as events of the children are described.The best summary is that, after a full reading, it is a "prayer book" deserving at least a few pages every morning or bedtime-to start your day off with some contemporary words of the Virgin.

Back to physics, apparitions are glimpses of what basic physics must call the pre-BigBang:"the Immediacy of the non-time, nonspace Statimuum", necessary for the Big Bang to have occurred about 15 billion years ago containing all the universe we know and have lived in.The Big Bang had to come from the pre-BigBangEternity-the Statimuum-which contains the all of the All of the Universe Immediately-the Unrestrained Infinite Immediacy beyond our understanding and perception-except by brief glimpses which My Heart Will Triumph describes, as do the apparition experiences of others over the centuries.'

Stimulated by Soldo, I find myself confirmed in proposing that there are several human phenomena which give glimpses of the Statimuum of a more generalized superficial Spirituality and are usually not even recognized as a touch of Eternity.All are "supernature"-beyond the limitations of the animal kingdom, because only humans have "conscious of consciousness",i.e., the soul enables functioning beyond nature.To be listed are complex human-only events requiring interactions leading to "spirit" which is felt as an exhilarating surge of transcendence no doubt a glimpse of the joyful 
Immediacy of the All in the pre-Big Bang.The listed, infra, are not "apparitions" but mini-glimpses of Spirit.They are not "perfect" because nature has it's errors and pollution; andhumans have the freedom for entropy as well as synthesis.

\section{A Few Routinely Overlooked Mini-Glimpses not Apparitions of Spirit}

A. Human Art-Matter in nature creates Spirit-Love from the Creator is even evident in molecular attractions which fill the universe.Just before receiving My Heart Will Triumph, I visited the Garfield Park Conservatory in Chicago.It is an artful collection of many plants with molecules provoking humans to imitate their natural transcendent organizing into more visible exhibition of transcendence provoking in humans even more genuine Spirit beyond the Universe.Suddenly, you see and feel love everywhere there is real Art, including in nature, as the Virgin told these kids:"Today I invite you to observe nature because there you will meet God.I call you to give glory to God the Creator in the colors of nature.Through even the smallest flower, He speaks to you about His beauty and the depth of His love" (page 81)-If you can see clearly, matter creates Spirit, because there is even "love" between molecules attracted to each other in nature.

B. Sports-Sports are spirit-filled interaction eventscontestants and spectators pray alot.

C. Music-Music with words of transcendence-being, matter, identity, truth, oneness, good, and beauty[1].
D. Words-Words and language cannot be understood by evolutionists, scientists, philosophers, or academics because "words are angels"[2]-Look them up in the Oxford English Dictionary and find their birth and personhood.

E. Theogeocalculus-Natural Law[3]-If you do not follow it, you are pollution.

F. The Mass-with its ultimate human purposes of Life, Sacrifice, Virtue, Love, Humanity, Peace, Freedom, and Natural Death Without Fear [4-6].

These human events all pale to the apparitions by the Virgin to the children, but genuine pre-BigBang Spirit is glimpsed and felt by involvement in these six human-only $\mathrm{C} 2$ (Conscious-ofConsciousness) categories beyond nature but not beyond Nature's God and super-nature.

My Heart Will Triumph is a must read consistent with the God given Lovelution of the Church and full humanbeingness.

\section{References}

1. On Listening To Music...Sam@DocNigro.com

2. Words Angels Language...Sam@DocNigro.com

3. The Theogeocalculus of Life.

4. Deplorable Pamphleteer...Sam @DocNigro.com

5. Samuel A Nigro (2015) The church. J Psychol Clin Psychiatry 4(3): 00216.

6. Does anyone know how to go to mass anymore?...Sam@DocNigro.com
Creative Commons Attribution 4.0 International License

For possible submissions Click Here

\section{Submit Article}

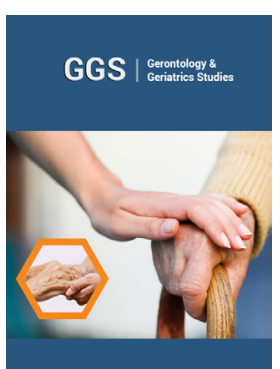

Gerontology \& Geriatrics Studies

\section{Benefits of Publishing with us}

- High-level peer review and editorial services

- Freely accessible online immediately upon publication

- Authors retain the copyright to their work

- Licensing it under a Creative Commons license

- Visibility through different online platforms 